\title{
EWA NOWAK-TETER
}

Maria Curie-Sklodowska University in Lublin (Poland)

\section{Review of Deep Mediatization, by Andreas Hepp, Routledge, London-New York 2020, pp. 248. ISBN: 978-351-06490-3}

In the time of COVID-2019 pandemic when the mediatization process swiftly progresses and takes the form of "rapid mediatization", the subject of Andreas Hepp's study published in 2020 is especially timely. One of the most important qualities offered by mediatization studies is overcoming or exceeding the assumptions of classic theories of media effects. In line with the mediatization concept we should not only observe the media impact on society, in particular on the individuals, but we also ought to pay attention to the multi-directional transformations which take place in media-related environments. In other words, we are both interested in how the media influence culture and society, but also in how the media (content, technologies, organizations) respond to social and cultural transformations forming mutual network of dependencies. Mediatization is sometimes misunderstood as a new concept of media effects. While mediatization generally concerns: “(...) media's role in transformation of culture and society" (Hepp, 2020, p. 56), it is not engaged or limited to theorizing about media effects. What Hepp offers instead is the understanding of mediatization as: "(...) the relationship between the transformation of media and communication on the one hand and culture and society on the other" (Hepp, 2020, pp. 3-40).

The book consists of seven chapters with the first the introductory one. In the second chapter, the author focuses on the actor-center approach to deep mediatization, where both the roles of corporate and community actors are discussed. What is more, in this part of the book, the quantitative trends of deep mediatization, including differentiation of media devices, rising omnipresence of mobile media, accelerated pace of innovation and datafication, are analysed. The third part is devoted to the processual nature of media, which is based on digitalization and "algorithmization". 
This processual nature causes that media exist in a state of continuous "beta". In the subsequent part, the figurational approach to analysis of deep mediatization is offered. Figurations are understood as constellations of actors who engage in communication using media technologies. The value of this approach lies in offering a conceptual and methodological framework that enables carrying out the relevant observations of mediatization process in the making. In particular, when using non-media centric perspective, the figurational approach provides tools for the analysis of the process of recursive transformation, which is named "re-figuration". The figurational approach is also used to analyse re-figuration of the habitus of individuals and transformation of society facing the process of deep mediatization (Chapters five and six). In the seventh chapter, the conclusion about deep mediatization process is inspired by its normative facets and the implications of mediatization for "the good life". What the author assumes, is that deep mediatization cannot be just stopped or reversed, and that the research and practical tasks should concentrate on the question of " $(. .$.$) what$ form mediatization should take to make a "good life" possible under the conditions it produces" (Hepp, 2020, p. 14).

The development of mediatization concept, including the notion of deep mediatization, offered in the book involves several elements. Firstly, mediatization is perceived as the "sensitizing concept", in the meaning that it gives us the chance to observe the media-related transformations in every context of our personal and societal life. These transformations should be empirically observed taking into account the historical depth of mediatization process, its implications for the process of modernization, as well as the diversity of media-related changes. The concept of deep mediatization reflects the new stage of mediatization process, in which the digitalization plays the most significant role, and where: "(...) all elements of our social world are intricately related to digital media and their underlying structures (Hepp, 2020, p. 5).

What the author proposes as a challenge for mediatization research, is that we have to take into account also the analysis of algorithms, big data and the implications related to artificial intelligence, which influence media environments and which will determine it in foreseeable future. The author suggests that the identification of mediatization is not the linear process, but takes the course of waves, involving fundamental changes taking place in media environments. This process is described as recursive, in the meaning that the rules of social change are inscribed in digital data and algorithms, and then they are reapplied in the process of governing the social change. In other words, the data reflecting the social media usage are gathered and analysed thanks to automated tracking, and the results of these analyses are then used to manage the social media-related behavior, which shapes the subsequent social media behavior.

Hepp applies both quantitative and qualitative analysis of deep mediatization, where the quantitative approach is focussed mainly on the proliferation of media and its technologies in society. The proliferation takes place in time, space and social dimensions. The qualitative approach is concerned with the ways in which society 
and human practices are transformed by the media ability to shape them. When acknowledging two main traditions of mediatization research, that is institutionalist and constructivist one, Hepp proposes to see them as converging in the main stream of deep mediatization. One of the key concepts developed within the institutionalist approach is the media logic (Altheide \& Snow, 1979), which is built on the conviction, that: "(...) institutional media forms not only help shape and guide content and numerous everyday activities, but also that audiences-as-actors normalize these forms and use them as reality maintenance tools" (Altheide, 2013, p. 225). The criticism of the concept of media logic introduced by Hepp is reflected in questioning the usefulness of the idea of single media logic that describes the established (more or less static) principles of media functioning. In line with the author's view, there is no single media logic but many media logics which are functioning in a dynamic technological and societal conditions. Although the concept of "many media logics" sounds convincing, especially when we take into account the multiplicity of the available technologies and devices, it seems that considering the common features of the "general media logic" emerging in different societal contexts could lead to valuable conclusions. For example, joining different media technologies in a single device can make the opportunity to investigate the examples of the united new media logic (studied using both in longitudinal and cross-sectional approach). Although there are undeniable differences between, for example, the organizational rules (also related to the formats, content, and production principles) the various kinds of media are subordinated to, the question which arises from these observations is whether and how certain general perspective encompassing the common features of various media logics can be worked out.

\section{References}

Altheide, D., \& Snow, R. (1979). Media Logic. Beverly Hills: Sage.

Altheide, D. (2013). Media Logic, Social Control and Fear. Communication Theory, 23, 223-238. Hepp, A. (2020). Deep Mediatization. London-New York: Routledge. 